\title{
Genetic Variants and Drug Efficacy in Tuberculosis: A Step toward Personalized Therapy
}

\author{
Almas Khan ${ }^{1}$ Mohammad Abbas ${ }^{1}$ Sushma Verma ${ }^{1}$ Shrikant Verma ${ }^{1}$ Aliya Abbas Rizvi ${ }^{1}$ \\ Fareya Haider $^{3}$ Syed Tasleem Raza ${ }^{2}$ Farzana Mahdi ${ }^{1}$ \\ ${ }^{1}$ Department of Personalized and Molecular Medicine, Era University, \\ Lucknow, Uttar Pradesh, India \\ ${ }^{2}$ Department of Biochemistry, Era's Lucknow Medical College and \\ Hospital, Lucknow, Uttar Pradesh, India \\ ${ }^{3}$ Department of Microbiology, Era's Lucknow Medical College and \\ Hospital, Lucknow, Uttar Pradesh, India \\ Address for correspondence Mohammad Abbas, PhD, Department of \\ Personalized and Molecular Medicine, Era University, Lucknow \\ 226003, Uttar Pradesh, India (e-mail: rizvi.109@gmail.com). \\ Glob Med Genet 2022;9:90-96.
}

\author{
Abstract \\ Keywords \\ - mycobacterium \\ tuberculosis \\ - germline variants \\ - anti-TB drug-related \\ toxicity \\ - pharmacogenomics \\ - personalized \\ medicine
}

Tuberculosis (TB) continues to be a major infectious disease affecting individuals worldwide. Current TB treatment strategy recommends the standard short-course chemotherapy regimen containing first-line drug, i.e., isoniazid, rifampicin, pyrazinamide, and ethambutol to treat patients suffering from drug-susceptible TB. Although Mycobacterium tuberculosis, the causing agent, is susceptible to drugs, some patients do not respond to the treatment or treatment may result in serious adverse reactions. Many studies revealed that anti-TB drug-related toxicity is associated with genetic variations, and these variations may also influence attaining maximum drug concentration. Thus, inter-individual diversities play a characteristic role by influencing the genes involved in drug metabolism pathways. The development of pharmacogenomics could bring a revolution in the field of treatment, and the understanding of germline variants may give rise to optimized targeted treatments and refine the response to standard therapy. In this review, we briefly introduced the field of pharmacogenomics with the evolution in genetics and discussed the pharmacogenetic impact of genetic variations on genes involved in the activities, such as anti-TB drug transportation, metabolism, and gene regulation.

\section{Introduction}

Tuberculosis (TB) continues to be a highly contagious public health threat, caused by bacillus Mycobacterium tuberculosis (MTB), ${ }^{1}$ and has been ranked above human immunodeficiency virus (HIV)/acquired immunodeficiency syndrome since 2007. ${ }^{2}$ About 10 million cases were recorded in the TB account, and 1.2 million who died were among HIV-infected people including 208,000 deaths of HIV-positive people. ${ }^{2}$ India is leading followed by Indonesia and China, among the eight countries, contributing to two-thirds of the total

received

December 22, 2021

accepted

January 21, 2022
DOI https://doi.org/

$10.1055 / \mathrm{s}-0042-1743567$.

ISSN 2699-9404. global TB burden. ${ }^{2}$ The disease remains a matter of grave concern as the graph of TB infection continues to incline in spite of highly efficacious treatment available since decades. Although with rapid diagnostic methods and treatment with the combination of drug regimens for over 50 years, the disease has evolved to high mortality and treatment failure. Drug response varies from individual to individual suffering from the same disease and on the same treatment plan, and some may experience adverse drug reactions (ADR). ${ }^{3}$ Nongenetic factors such as age, gender, nutritional status, general medical condition (e.g., hepatic and renal physiology), (c) 2022. The Author(s).

This is an open access article published by Thieme under the terms of the Creative Commons Attribution License, permitting unrestricted use, distribution, and reproduction so long as the original work is properly cited. (https://creativecommons.org/licenses/by/4.0/) Georg Thieme Verlag KG, Rüdigerstraße 14, 70469 Stuttgart, Germany 
lifestyle (diet, alcohol abuse, and smoking), concomitant therapy, or the presence of co-morbidity have been previously attributed to differences in the risk-benefit ratio among patients taking the same drug. Aside from these considerations, changes in patient genetic make-up are now understood to have a significant impact on treatment response. ${ }^{4}$ These variations among individuals are due to several factors including different allele frequency distributions of single nucleotide polymorphisms (SNPs) that have a functional impact on genes association with drug response. ${ }^{5}$ Hence, absorption, distribution, metabolism and excretion, pharmacokinetics (PK), and pharmacodynamics of drugs are influenced by a genetic variation which affects drug efficacy and drug-induced toxicity and, thus, leads to ADRs or therapeutic failure. All these factors due to variations are validated by genotypes, and therefore, pharmacogenetic implementation in the clinical setting has become an important aspect of targeted therapy. ${ }^{6}$ Pharmacogenomics research has a longterm purpose of the development of individualized medication based on the patient's genetic sequence to achieve maximum response and avoid undesirable drug responses. ${ }^{7}$

Isoniazid (INH), rifampicin (RF), pyrazinamide, and ethambutol are the first-line anti-TB drugs currently recommended by World Health Organization. ${ }^{2}$ INH and RF are the two key drugs used for the treatment of TB. Resistance offered to these drugs by the mycobacteria or adverse reaction caused by the drugs results in treatment prolongation from 6 to 9 months $^{8}$ or sometimes treatment has to be stopped due to the excessive damaged caused by the adverse reaction. ${ }^{9}$ Efficacy and early antibacterial activity of the drugs are related to the dose or PK; therefore, the variation in the PK of INH and RF influences the clinical consequence of TB treatment. ${ }^{9}$ With beneficial effects, there are various adverse effects especially peripheral neuropathy and hepatotoxicity induced by INH therapies. ${ }^{10,11}$ We have outlined the emerging role of pharmacogenomics in this review and the way in which valuable tools for the determination of inter-individual variation are found. In this review, we focus on genes involved in RF and INH transport and metabolism, as well as the genes governing the transcription of transporter and metabolizing genes.

\section{Genetics and Individualized Treatment (Personalized Medicine)}

The idea of individualized medicine is an appealing concept for the future of treatment. It is divine to employ molecular research data to categorize disease and its susceptibility, aid the development and rationale of new therapeutic regimen, ${ }^{12}$ and help in patient treatment with greater specificity and potency with fewer side effects ${ }^{13}$ (- Fig. 1).

With the advancement in technology and development in biomedical sciences, research findings have unfolded several predictive sciences. Pharmacogenetics and pharmacogenomics are two among new predictive sciences that have emerged from the knowledge discovered in biomedical research. The research in these fields could promise a crucial step toward personalized treatment. ${ }^{14}$ It is necessary to understand the disposition and fate of drugs, i.e., PK and pharmacodynamics of drugs which include therapeutic outcomes with adverse effects. The PK and pharmacodynamics of drugs are determined by complicated processes involving the majority of proteins coded by a variety of genes, which determine drug transport, metabolism, potency, and drug detoxification. Variations in the coding region may induce amino acid substitution at the specific location of protein

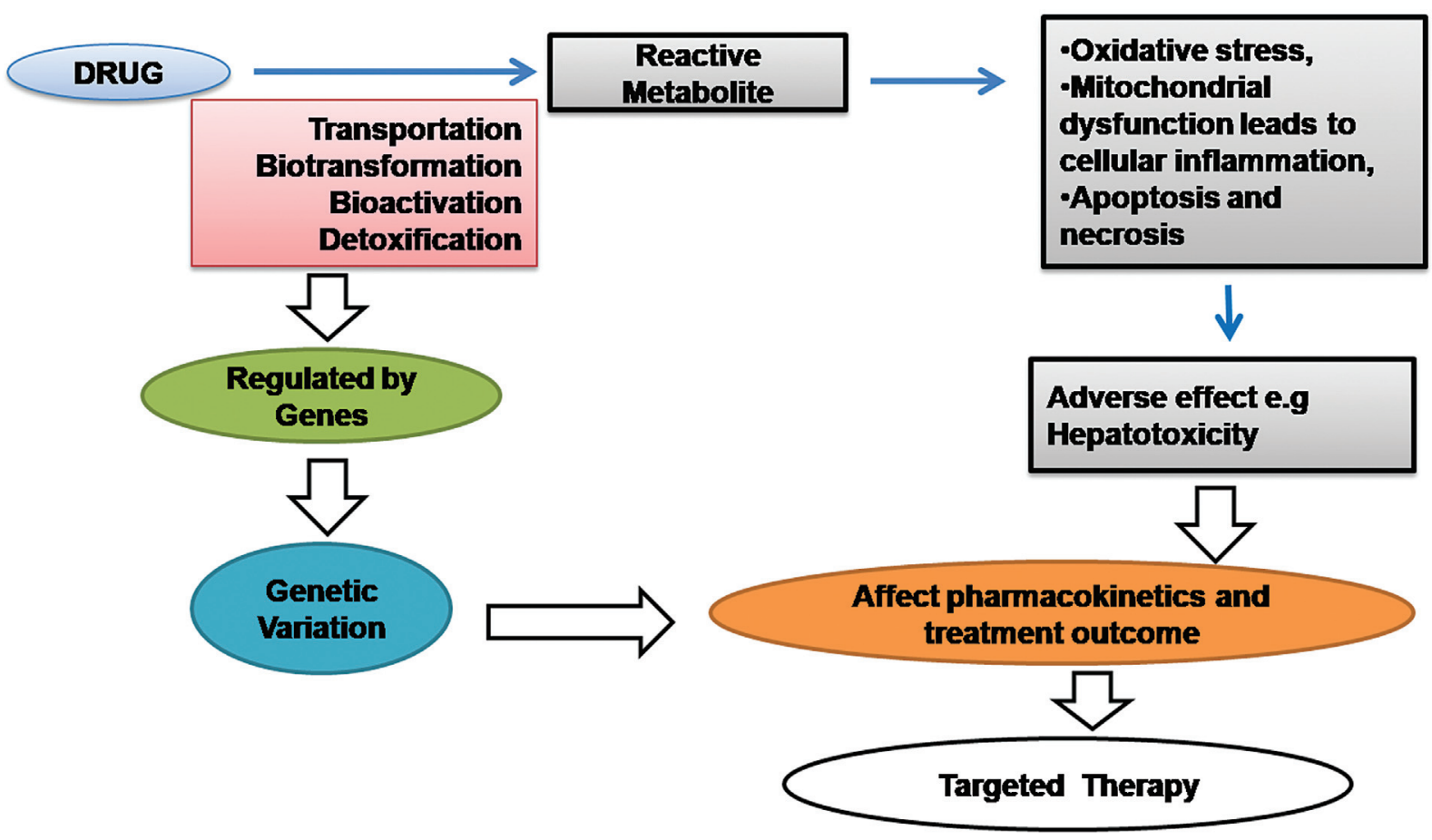

Fig. 1 Concept of genotyping-based targeted/individualized therapy. 
which consequently alters protein function. If the variation is found in the regulatory region, it may affect transcription and translational mechanisms with gene product modulation (mRNA and proteins) and their expression levels may differ. $^{4,15}$ Variations in DNA sequence in population at or above $1 \%$ allelic frequency are termed as polymorphism, whereas variations with lower frequencies are defined as mutations. Metabolic activities or drug affinity to its receptor and efficacy depends on enzymes coded by mutated or polymorphic genes, which can alter pharmacological response in individuals or in some ethnic groups, within population. Single-nucleotide polymorphisms (SNPs) are a type of genetic variants that occur mostly as a result of the substitution of a single base pair and they are commonly known. ${ }^{4,15}$ Studies revealed that variability among individuals in PK vulnerability to drug accounts for some unfortunate outcomes, also in those patients who do not miss doses. This has challenged the conventional concept that therapeutic failure, reoccurrence, and the emergence of antimicrobial resistance are primarily due to poor adherence. ${ }^{16}$

The severe and ubiquitous challenge in the TB management of patients is PK heterogeneity. SLCO1B 1, ABCB1, PXR, $C A R$, and $C E S$ genetic variations have drawn scientific attention because they have an impact on a broad spectrum of medications' PK. ${ }^{17}$ Genetic changes in the acetylation status are linked to marked inter-individual variation in circulating INH concentration and clearance after medication. The differences in INH inactivation and elimination rates in various (fast and slow) acetylation phenotypes are principally attributable to differences in the rate of INH acetylation in the liver and small intestine by a genetically regulated polymorphic $\mathrm{N}$-acetyltransferase (NAT) enzyme. ${ }^{18}$

\section{Rifampicin}

RF proved to be a cornerstone TB treatment by shortening the period of anti-tubercular therapy (ATT) from 18 to 9 months and enhanced recovery rates when it was introduced in combinational chemotherapy for TB during 1960 s. $^{19,20}$ RF diffuses freely in the tissues, living cells, and bacteria which make it easily available against the intracellular pathogens like MTB. It exhibits its anti-mycobacterial activity by arresting the RNA synthesis from MTB's DNA through the $\beta$-subunit of RNA polymerase (RNA pol). ${ }^{21}$ RF action drives through the rpo $\beta$ gene which codes for the $\beta$ subunit of RNA pol, and mutation in the rpo $\beta$ gene is the reason behind the development of more than $95 \%$ of resistance against RF. Major mutation hotspots are found in $81 \mathrm{bp}-$ $\mathrm{RF}$ resistance-determining region (RRDR). Commonly known mutated codons in RRDR are rpo $\beta$ 531, rpo $\beta$ 526, and rpo $\beta$ $516 .^{22}$ Its antibacterial properties and resistance development are influenced by drug bioavailability (concentration), and higher doses of $1,200 \mathrm{mg}$ or more daily may be effective. ${ }^{23}$ As a result, increasing the dose of RF from the standard dosing based on weight may aid in achieving desired plasma PK and pharmacodynamics. ${ }^{24}$ Few recent studies have shown that the high dosage of RF could result in better therapy outcomes in patients. ${ }^{25,26}$ Many studies reported a correlation between various genetic variants and significant changes in RF plasma levels in TB patients. ${ }^{27}$ RF hepatocellular uptake is typically performed by organic aniontransporting polypeptide 1B1 (OATP1B1) ${ }^{28}$ and metabolism is catalyzed by hepatic $\beta$ esterases and arylacetamide deacetylase $^{29}$ to its active metabolic form, 25-desacetylrifampicin, and then, it is excreted via bile and renal routes after first pass metabolism. ${ }^{30}$ OATP1B1 is main among the major influx transporter proteins, a 691 amino acid protein coded by solute carrier (SLC) organic anion transporter family member 1B1 (SLCO1B1) ${ }^{31}$ gene that predominantly presents at the basolateral membrane of hepatocytes ${ }^{32}$ and modulates the hepatic uptake of drug from bloodstream. ${ }^{33}$ OATP1B1 transporter protein has a strong affinity for $\mathrm{RF}^{34}$ Membrane drug transporter superfamilies include SLC and adenosine triphosphate (ATP)-binding cassette (ABC) transporters. ${ }^{32}$ Around 400 transporters in membrane belong to SLC and ABC superfamily, with approximately 32 of them being clinically linked and potentially important drivers of drug PK and individual drug responses. ${ }^{35}$ The sinusoidal inflow transporter SLCO1B1 and the efflux transporter ABCB1 influence RF distribution ${ }^{36}$ while absorption in liver and biliary excretion. ${ }^{37}$ Fifteen exons and 190 known polymorphisms having minor allele of more than $5 \%$ frequency are found in the SLCO1B1 gene. ${ }^{38}$ rs4149056 625T >C and rs2306283 492A $>\mathrm{G}$ are two well-characterized variation in the SLCO1B1 gene ${ }^{39}$ (-Fig. 2).

According to studies, a common single nucleotide variant (rs4149056 c.521T > C p. V174A) reduces SLCO1B1 expression, resulting in lower OATP1B1 uptake/transport activity and higher plasma levels. ${ }^{40}$ Allegra et al reported high RF plasma concentration in TB patients with the SLCO1B1 rs4149056 variant, and analysis by multivariate linear regression also suggested that the SLCO1B1 rs4149056 variant can be considered as a positive predictive marker for raised RF concentration. ${ }^{41}$ Weiner et al observed decreased RF exposure in patients who had SLCO1B1 rs11045819 (c.463C $>$ A p. Pro155Thr) polymorphism. ${ }^{42}$ When compared with patients with the wild-type allele (CC), patients having rs11045819 variant allele (CA) in SLCO1B1 showed $42 \%$ low RF exposure $(25.6 \mu \mathrm{g} * \mathrm{~h} / \mathrm{mL}), 34 \%$ reduced peak concentration $(5 \mu \mathrm{g} / \mathrm{L})$, and $63 \%$ detectable oral clearance $(22 \mathrm{~L} / \mathrm{h}) .{ }^{42}$ The functional effects of variation rs2306283 (c.388A > G p. Asn130Asp) have been observed to be inconsistent. ${ }^{40,43} \mathrm{~A}$ study by Dompreh et al observed that rs2306283 variant in SLCO1B1 was found to be related to decreased RF concentration in pediatric TB patients. In paired analysis, patients having SLCO1B1 homozygous variation (AA) exhibited significantly lesser RF concentration than patients having wild genotype (GG) ${ }^{44}$ In the African population, there is an elevation in the prevalence of the SLCO1B1 rs4149032 polymorphism in intron 2 haplotype tagging SNP (tSNP) which is associated with lower RF exposure. ${ }^{45}$ Patients with heterozygous and homozygous mutations had considerably lower RF bioavailability, with 18 and 28\% declines in RF bioavailability, respectively. ${ }^{46}$

RF is a substrate of P-glycoprotein (Pgp) efflux pump. ${ }^{47}$ Pgp is a multi-domain integer membrane protein that uses 


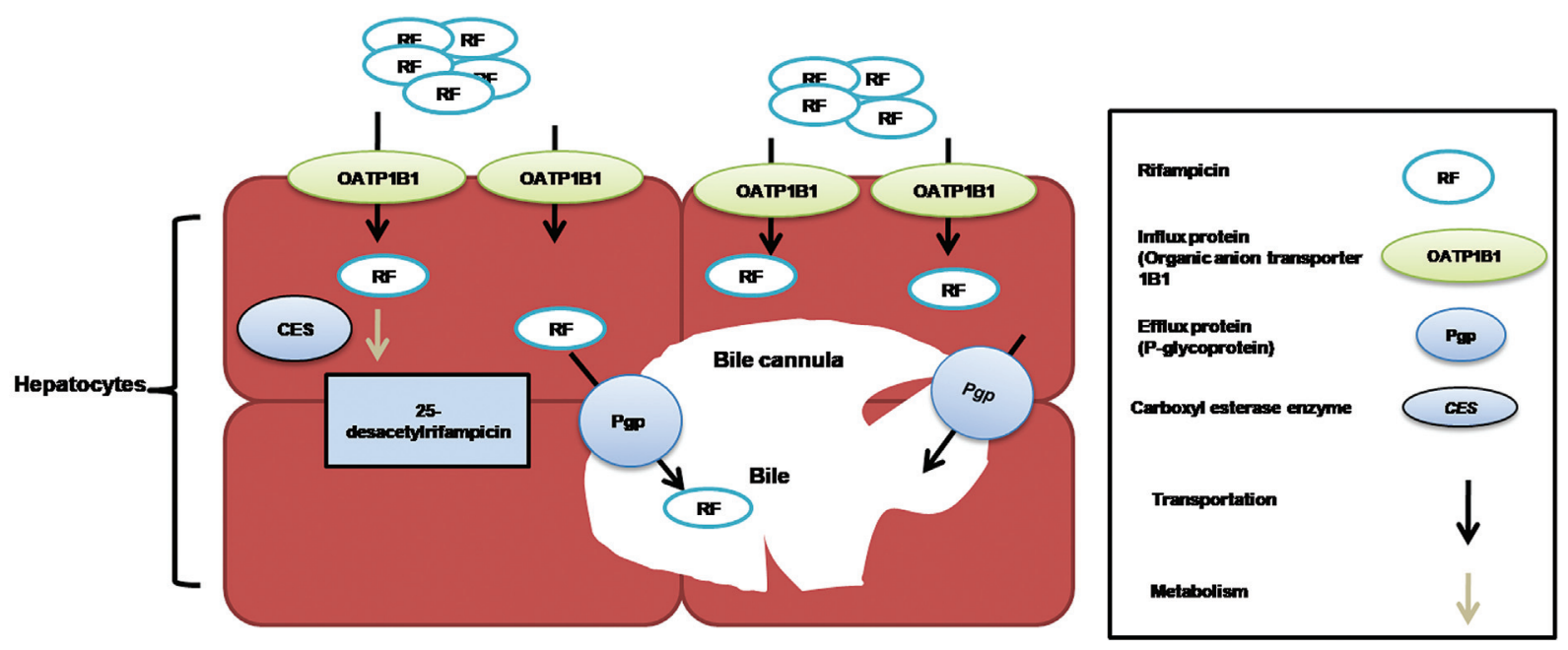

Fig. 2 Diagram showing the uptake, transformation, and efflux of rifampicin in hepatocytes.

ATP energy to move solutes/ions across the membranes in eukaryotes (efflux pump). ${ }^{48-50}$ Pgp is the ABCB1 transporter protein constituting of 1,280 amino acids that is encoded by the $A B C$ gene. ${ }^{51}$ The $A B C B 1$ gene is present on chromosome number 7 and has 29 exons in a 251.3-kb genomic area. The most prevalent SNPs in this ABCB1 gene are rs1128503, rs2032582, and rs1045642. ${ }^{52}$ rs1128503 and rs 1045642 variants are synonymous, while missense mutation is found in rs2032582. ${ }^{53}$ There was no statistically significant correlation between $A B C B 1$ variants and $R F P K$ in any of the studies. However, only few of $A B C B 1$ variants were studied in relation to RF exposures. Rare ABCB1 mutations that could affect medication PK have yet to be thoroughly investigated in terms of their functional consequences. ${ }^{52}$ The transcription of SLCO1B1 and ABCB1 genes is regulated by PXR and $C A R$ genes. PXR and CAR are nuclear receptors in the group I family that regulate a variety of transcriptions, including those of medicinal enzymes and drug transporter genes. ${ }^{52}$ Few research studies have looked into the likelihood of SNPs in these genes being linked to RF plasma levels. The PXR gene has rs2472677 and rs1523130 variations in the intron 1 and 50UTR regions, respectively. These areas illustrate the transcription factor binding sites of regulatory regions of $P X R .^{53}$ rs2307424 variant is due to synonymous mutation in the CAR gene (c.540 C > T). ${ }^{54}$ None of the variants have found to be associated with the RF plasma level and its exposure.

B-esterase is the enzyme that converts RF to 25-desacetylrifampin. ${ }^{55}$ The carboxylesterase (CES), acetylcholinesterase, and butyrylcholinesterase enzymes are all members of the B-esterase family. CES is a broad substrate-specific enzyme that hydrolyzes ester, thioester, amide, and carbamate bonds, which is implicated in the metabolism of various endobiotic and xenobiotic substances. The two primary isoenzymes of human CES, mainly expressed in the liver, are CES1 and CES2, which are coded by the CES1 and CES2 genes, respectively. ${ }^{56}$ Several genetic variants of CES1 and CES2 have been associated with a significant difference in drug therapy responses over the past decades. As a result, comparing the PK of substrate medicines to genetic variations in these genes becomes important. ${ }^{57}$ Both
CES1 and CES2 genes lie on chromosome 16 and have 14 and 12 exons, respectively. ${ }^{58}$ Sloan et al found that rs12149368 mutation in the exon 1 (5'UTR) region in CES1 gene has no effect on plasma RF concentration. ${ }^{16}$ Song et al observed 10 SNPs: the promoter region variants $\mathrm{c}-2548 \mathrm{C}>\mathrm{T}$ and $\mathrm{c}-2263 \mathrm{~A}>\mathrm{G}$, as well as c.269-965A $>$ G, c.474-152T $>$ C, c.615 + 120G $>A$, c.1612 $+136 \mathrm{G}>\mathrm{A}$, and c.1613-87 G > A variants in intronic region and c. $1872 * 69 A>$ G, c. $1872 * 302 \_304 d e l G A A$, c. $1872 * 445 C>$ G variants in 3'UTR within the RF level. The CES2 c.-22263A>G variation was linked to elevated concentration of RF in plasma in TB patients. Plasma RF concentrations in homozygous major, heterozygous, and homozygous minor allele were $8.9 \pm 2.9$, $10.5 \pm 3.1$, and $13.9 \pm 7.4 \mathrm{mg} / \mathrm{L}$, respectively, in homozygous major allele, heterozygous, and homozygous carrying minor allele. The shift of $G$ from $A$ in the CES2 c.-22263A > G variant has been found linked with continuous fall in activity of luciferase, this may lead to low metabolism and higher plasma RF levels, according to the study. ${ }^{59}$ Dompreh et al, on the contrary, found no differences in exposures of RF with CES2 rs3759994 variation. $^{9}$

\section{Isoniazid}

Due to low molecular weight and high water solubility, ${ }^{18}$ INH can be easily absorbed from the gastrointestinal tract (GIT) 4,60 ; thus, the peak plasma concentration reaches in 1 to 3 hours of drug intake. ${ }^{61}$ INH reaches all tissues ${ }^{62}$ and body fluids including cerebrospinal fluid, saliva, pleural, and peritoneal fluid ${ }^{63}$ and to lungs after absorption from GIT. ${ }^{64,65}$ INH also attains peak concentration in the breast milk of lactating mother within 1 hour of drug administration. ${ }^{66}$

INH metabolism mainly follows enzyme-dependent pathways such as acetylation through NAT2 enzyme and hydrolysis catalyzed by acyl amidase. ${ }^{67}$ INH-NAD $^{+}$adducts is also formed by the combined action of human neutrophil myeloperoxidase and catalase-peroxidase $(K A T G)$ of MTB. ${ }^{68,69}$

INH is initially metabolized by a non-inducible hepatic and intestinal enzyme known as the NAT type 2 (NAT2) ${ }^{67}$ which is coded by highly polymorphic gene called NAT 2 
gene. ${ }^{70}$ INH is acetylated to acetylisoniazid by NAT2 enzyme 2 , and it is also hydrolyzed to form isonicotinic acid (INA) and hydrazine $(\mathrm{Hz})$ through the amidase enzyme. Acetylisoniazid can also be hydrolyzed to produce INA and acetylhydrazine $(\mathrm{AcHz})$; furthermore, $\mathrm{Hz}$ can be converted into $\mathrm{AcHz}$ and diacetylhydrazine via acetylation catalyzed by NAT2 enzyme. $^{71} \mathrm{~Hz}$ and $\mathrm{AcHz}$ are supposed to be converted into reactive metabolites through oxidation and may be responsible for the INH hepatotoxicity which can be mediated by microsomal P450s like CYP2 E. ${ }^{67,72}$

Arylamine NAT (EC2.3.1.5) is the cytosolic enzyme of $30 \mathrm{kDa}$ found in almost every species, both in prokaryotes and in eukaryotes. ${ }^{73}$ It is present in multiple isoenzymes forms, ${ }^{74}$ and its two distinct isoforms, NAT1 and NAT2, with overlapping substrate specificities have been studied in humans. ${ }^{75}$ Biotransformations of xenobiotics are mainly catalyzed by NAT1 and NAT2 ${ }^{74}$ NAT2 expression is confined to liver and GIT, whereas NAT1 is expressed in the majority of the tissues along with endocrine tissues, blood cells, neural tissues, as well as in liver and GIT. ${ }^{76}$ Being a transferase group of enzyme, it inactivates the arylamine and Hz-based xenobiotics by transferring acetyl group of acetyl CoA to the terminal nitrogen atom of the xenobiotics. ${ }^{18}$ Hence, it is accountable for $\mathrm{Hz}$ drug acetylation and many carcinogenic aromatic amines along with endogenous molecules such as serotonin. $^{67}$

NAT1 enzyme is limited to few specific substrates (paminobenzoic acid), whereas NAT2 enzymes ${ }^{76}$ play a crucial role in the metabolism of a wide variety of drugs like dapsone, sulfadoxine, INH, procainamide, and hydralazine along with chemicals which are present in the diet. ${ }^{77}$ NAT1 and NAT2 genes encode NAT1 and NAT2 enzymes, respectively. ${ }^{78}$ The NAT2 is autosomal dominant and intronless having a single open reading frame of 870 base pairs, located on chromosome 8p22. Variations in NAT2 result in slow, intermediate, or fast acetylation phenotypes with broad inter-ethnic groups. NAT2 confer slow, intermediate, or fast acetylation phenotypes with broad interethnic variations. There are 53 NAT2 alleles presently known, and each allelic variant exhibits the combination of one, two, three, or four nucleotide alteration. There are seven missense mutations (G191A, T341C, A434C, G590A, A830G, A845C, and G857A) and four silent mutations (T111C, C282T, C481T, and $\mathrm{C759A}$ ) within the coding region. ${ }^{5}$ The NAT2* 4 is a wildtype allele, does not have any nucleotide substitution, and is known to be associated with the fast acetylation phenotype. This acetylation phenotype can be predicted by genotyping with $95 \%$ accuracy.

Considering genetic characteristics of NAT2 enzymes, the ability of drug and exogenous compound acetylation and inter-individual variation among the population is widely related. ${ }^{79}$ As NAT2 enzyme is a dominant catalyzer in INH biotransformation (formation of AcINH), bio-activation (formation of $\mathrm{AcHz}$ ) and detoxification (formation of $\mathrm{DiAcHZ}$ ), due to different allelic distributions of NAT2 gene, results in variation in the acetylation profile of drugs in the same population. ${ }^{67,70}$ The degree of acetylation has been associated with a higher risk of INH-induced hepatotoxicity in various studies. There are three different phenotypic acetylation profiles based on SNPs in the exon of the NAT2 gene. Individuals with slow NAT2 acetylation allele have a low acetylation rate, resulting in a higher plasma concentration of the parent drug and possibly better efficacy. However, individuals with slow acetylation may experience adverse effects due to the accumulation of toxic metabolites such as $\mathrm{AcHz}$ during the ongoing metabolism of INH and toxic metabaolites contributing to hepatitis threat. Fast acetylation causes low plasma drug concentrations, making them less toxic and also less effective, while intermediate acetylation leads to in-between results. ${ }^{80}$ Alleles of slow acetylation have been found to be associated with increased risk of INH hepatotoxicity in numerous clinical investigations. ${ }^{67}$ Individuals with slow acetylation had higher plasma levels of INH and $\mathrm{AcHz}$ than those with fast acetylation. According to Donald et al, in slow acetylation of INH, $3 \mathrm{mg} / \mathrm{kg}$ dose is sufficient to attain the expected therapeutic objectives of anti-TB treatment, but in the case of fast acetylation, a $6 \mathrm{mg} / \mathrm{kg}$ of dose is required to provide adequate bactericidal activity. ${ }^{81}$

\section{Conclusion}

The genetic and molecular research has proved to be a cornerstone in personalized medicine and is indicative of its expanding importance in the field of health care. Heterogeneous drug response with anti-tubercular drug therapy is a severe problem in TB patients. So, here we emphasized the genetic association with the PK of ATT drug. Genetic polymorphism in drug transporter genes, regulatory genes like SLCO1B, ABCB1, PXR, and CAR and drug-metabolizing genes such as CES and NAT2 which drive the response, has been found to be of keen interest to rule out disease predisposition. By implementing genotyping assays prior to treatment administration, clinicians could better determine the dose which could be the main prospect of precision medicine. Additional studies are required to gain the core knowledge of drug fate association with genetic variations within the population. With advances in knowledge and findings, pharmacogenetics and pharmacogenomics will have a greater impact on drug research and development, clinical trials, and clinical practice.

\section{Funding}

None.

Conflict of Interest

None declared.

\section{References}

1 Barberis I, Bragazzi NL, Galluzzo L, Martini M. The history of tuberculosis: from the first historical records to the isolation of Koch's bacillus. J Prev Med Hyg 2017;58(01):E9-E12

2 World Health Organisation report, 2020. Accessed September 27, 2021 at: https://apps.who.int/iris/bitstream/handle/10665/336069/ 9789240013131-eng.pdf 
3 Ramamoorthy A, Pacanowski MA, Bull J, Zhang L. Racial/ethnic differences in drug disposition and response: review of recently approved drugs. Clin Pharmacol Ther 2015;97(03):263-273

4 Relling MV, Giacomini KM. Pharmacogenetics. In: Brunton LL, Lazo GS, Parker KL, eds. Goodman \& Gilman's. The Pharmacological Basis of Therapeutics, XI edizione. New York: McGraw-Hill Medical Publishing Division; 2006, chapter 4: 93-115

5 Bachtiar M, Ooi BNS, Wang J, et al. Towards precision medicine: interrogating the human genome to identify drug pathways associated with potentially functional, population-differentiated polymorphisms. Pharmacogenomics J 2019;19(06): 516-527

6 Barbarino JM, Whirl-Carrillo M, Altman RB, Klein TE. PharmGKB: a worldwide resource for pharmacogenomic information. Wiley Interdiscip Rev Syst Biol Med 2018;10(04):e1417

7 O'Donnell PH, Dolan ME. Cancer pharmacoethnicity: ethnic differences in susceptibility to the effects of chemotherapy. Clin Cancer Res 2009;15(15):4806-4814

8 Getahun H, Matteelli A, Abubakar I, et al. Management of latent Mycobacterium tuberculosis infection: WHO guidelines for low tuberculosis burden countries. Eur Respir J 2015;46(06): 1563-1576

9 Dompreh A, Tang X, Zhou J, et al. Effect of genetic variation of NAT2 on isoniazid and SLCO1B1 and CES2 on rifampin pharmacokinetics in Ghanaian children with tuberculosis. Antimicrob Agents Chemother 2018;62(03):e02099-17

10 Metushi IG, Cai P, Zhu X, Nakagawa T, Uetrecht JP. A fresh look at the mechanism of isoniazid-induced hepatotoxicity. Clin Pharmacol Ther 2011;89(06):911-914

11 Carlson HB, Anthony EM, Russell WF Jr, Middlebrook G. Prophylaxis of isoniazid neuropathy with pyridoxine. N Engl J Med 1956; 255(03):119-122

12 Lander ES, Linton LM, Birren B, et al; International Human Genome Sequencing Consortium. Initial sequencing and analysis of the human genome. Nature 2001;409(6822):860-921

13 Venter JC, Adams MD, Myers EW, et al. The sequence of the human genome. Science 2001;291(5507):1304-1351

14 Wilke RA, Lin DW, Roden DM, et al. Identifying genetic risk factors for serious adverse drug reactions: current progress and challenges. Nat Rev Drug Discov 2007;6(11):904-916

15 Court MH. A pharmacogenomics primer. J Clin Pharmacol 2007; 47(09):1087-1103

16 Sloan DJ, McCallum AD, Schipani A, et al. Genetic determinants of the pharmacokinetic variability of rifampin in Malawian adults with pulmonary tuberculosis. Antimicrob Agents Chemother 2017;61(07):e00210-e00217

17 Thomas L, Miraj SS, Surulivelrajan M, Varma M, Sanju CSV, Rao M. Influence of single nucleotide polymorphisms on rifampin pharmacokinetics in tuberculosis patients. Antibiotics (Basel) 2020;9 (06):307

18 Weber WW, Hein DW. Clinical pharmacokinetics of isoniazid. Clin Pharmacokinet 1979;4(06):401-422

19 Murray JF, Schraufnagel DE, Hopewell PC. Treatment of tuberculosis. A historical perspective. Ann Am Thorac Soc 2015;12(12): 1749-1759

20 Maggi N, Pasqualucci CR, Ballotta R, Sensi P. Rifampicin: a new orally active rifamycin. Chemotherapy 1966;11(05):285-292

21 Campbell EA, Korzheva N, Mustaev A, et al. Structural mechanism for rifampicin inhibition of bacterial RNA polymerase. Cell 2001; 104(06):901-912

22 Zaw MT, Emran NA, Lin Z. Mutations inside rifampicin-resistance determining region of rрoB gene associated with rifampicinresistance in Mycobacterium tuberculosis. J Infect Public Health 2018;11(05):605-610

23 Gumbo T, Louie A, Deziel MR, et al. Concentration-dependent Mycobacterium tuberculosis killing and prevention of resistance by rifampin. Antimicrob Agents Chemother 2007;51(11): $3781-3788$
24 Stott KE, Pertinez H, Sturkenboom MGG, et al. Pharmacokinetics of rifampicin in adult TB patients and healthy volunteers: a systematic review and meta-analysis. J Antimicrob Chemother 2018;73(09):2305-2313

25 Seijger C, Hoefsloot W, Bergsma-de Guchteneire I, et al. High-dose rifampicin in tuberculosis: experiences from a Dutch tuberculosis centre. PLoS One 2019;14(03):e0213718

26 Svensson EM, Svensson RJ, Te Brake LHM, et al. The potential for treatment shortening with higher rifampicin doses: relating drug exposure to treatment response in patients with pulmonary tuberculosis. Clin Infect Dis 2018;67(01):34-41

$27 \mathrm{Kim}$ RB. Organic anion-transporting polypeptide (OATP) transporter family and drug disposition. Eur J Clin Invest 2003;33 (Suppl 2):1-5

28 Tirona RG, Leake BF, Wolkoff AW, Kim RB. Human organic anion transporting polypeptide-C (SLC21A6) is a major determinant of rifampin-mediated pregnane $\mathrm{X}$ receptor activation. J Pharmacol Exp Ther 2003;304(01):223-228

29 Liederer BM, Borchardt RT. Enzymes involved in the bioconversion of ester-based prodrugs. J Pharm Sci 2006;95(06):1177-1195

30 Nakajima A, Fukami T, Kobayashi Y, Watanabe A, Nakajima M, Yokoi T. Human arylacetamide deacetylase is responsible for deacetylation of rifamycins: rifampicin, rifabutin, and rifapentine. Biochem Pharmacol 2011;82(11):1747-1756

31 Boivin AA, Cardinal H, Barama A, Pichette V, Hébert MJ, Roger M. Organic anion transporting polypeptide 1B1 (OATP1B1) and OATP1B3: genetic variability and haplotype analysis in white Canadians. Drug Metab Pharmacokinet 2010;25(05):508-515

32 Giacomini KM, Huang SM, Tweedie DJ, et al; International Transporter Consortium. Membrane transporters in drug development. Nat Rev Drug Discov 2010;9(03):215-236

33 Niemi M. Role of OATP transporters in the disposition of drugs. Pharmacogenomics 2007;8(07):787-802

34 Vavricka SR, Van Montfoort J, Ha HR, Meier PJ, Fattinger K. Interactions of rifamycin SV and rifampicin with organic anion uptake systems of human liver. Hepatology 2002;36(01): 164-172

35 Hillgren KM, Keppler D, Zur AA, et al; International Transporter Consortium. Emerging transporters of clinical importance: an update from the International Transporter Consortium. Clin Pharmacol Ther 2013;94(01):52-63

36 Guo YX, Xu XF, Zhang QZ, et al. The inhibition of hepatic bile acids transporters Ntcp and Bsep is involved in the pathogenesis of isoniazid/rifampicin-induced hepatotoxicity. Toxicol Mech Methods 2015;25(05):382-387

37 Te Brake LH, Russel FG, van den Heuvel JJ, et al. Inhibitory potential of tuberculosis drugs on ATP-binding cassette drug transporters. Tuberculosis (Edinb) 2016;96:150-157

38 Internet source. Accessed on September 1, 2021 at: www.hapman.com

39 Oshiro C, Mangravite L, Klein T, Altman R. PharmGKB very important pharmacogene: SLCO1B1. Pharmacogenet Genomics 2010;20(03):211-216

40 Niemi M, Pasanen MK, Neuvonen PJ. Organic anion transporting polypeptide 1B1: a genetically polymorphic transporter of major importance for hepatic drug uptake. Pharmacol Rev 2011;63(01): 157-181

41 Allegra S, Fatiguso G, Calcagno A, et al. Role of vitamin D pathway gene polymorphisms on rifampicin plasma and intracellular pharmacokinetics. Pharmacogenomics 2017;18(09):865-880

42 Weiner M, Peloquin C, Burman W, et al. Effects of tuberculosis, race, and human gene SLCO1B1 polymorphisms on rifampin concentrations. Antimicrob Agents Chemother 2010;54(10): 4192-4200

43 Lee $\mathrm{HH}, \mathrm{Ho} \mathrm{RH}$. Interindividual and interethnic variability in drug disposition: polymorphisms in organic anion transporting polypeptide 1B1 (OATP1B1; SLCO1B1). Br J Clin Pharmacol 2017;83 (06):1176-1184 
44 Dompreh A, Tang X, Zhou J, et al. Effect of genetic variation of NAT2 on isoniazid and SLCO1B1 and CES2 on rifampin pharmacokinetics in Ghanaian children with tuberculosis. Antimicrob Agents Chemother 2018;62(03):e02099-e17

45 Chigutsa E, Visser ME, Swart EC, et al. The SLCO1B1 rs4149032 polymorphism is highly prevalent in South Africans and is associated with reduced rifampin concentrations: dosing implications. Antimicrob Agents Chemother 2011;55(09): 4122-4127

46 Gengiah TN, Botha JH, Soowamber D, Naidoo K, Abdool Karim SS. Low rifampicin concentrations in tuberculosis patients with HIV infection. J Infect Dev Ctries 2014;8(08):987-993

47 Schuetz EG, Schinkel AH, Relling MV, Schuetz JD. P-glycoprotein: a major determinant of rifampicin-inducible expression of cytochrome P4503A in mice and humans. Proc Natl Acad Sci USA 1996;93(09):4001-4005

48 Jones PM, George AM. The ABC transporter structure and mechanism: perspectives on recent research. Cell Mol Life Sci 2004;61 (06):682-699

49 Gottesman MM, Hrycyna CA, Schoenlein PV, Germann UA, Pastan I. Genetic analysis of the multidrug transporter. Annu Rev Genet 1995;29:607-649

50 Wolking S, Schaeffeler E, Lerche H, Schwab M, Nies AT. Impact of genetic polymorphisms of ABCB1 (MDR1, P-Glycoprotein) on drug disposition and potential clinical implications: update of the literature. Clin Pharmacokinet 2015;54(07):709-735

51 Caraba A, Crişan V, Romoşan I, Mozoş I, Murariu M. Vitamin D status, disease activity, and endothelial dysfunction in early rheumatoid arthritis patients. Dis Markers 2017;2017:5241012

52 Hodges LM, Markova SM, Chinn LW, et al. Very important pharmacogene summary: ABCB1 (MDR1, P-glycoprotein). Pharmacogenet Genomics 2011;21(03):152-161

53 Fung KL, Gottesman MM. A synonymous polymorphism in a common MDR1 (ABCB1) haplotype shapes protein function. Biochim Biophys Acta 2009;1794(05):860-871

54 Jinno H, Tanaka-Kagawa T, Hanioka N, et al. Identification of novel alternative splice variants of human constitutive androstane receptor and characterization of their expression in the liver. Mol Pharmacol 2004;65(03):496-502

55 Jamis-Dow CA, Katki AG, Collins JM, Klecker RW. Rifampin and rifabutin and their metabolism by human liver esterases. Xenobiotica 1997;27(10):1015-1024

56 Ross MK, Crow JA. Human carboxylesterases and their role in xenobiotic and endobiotic metabolism. J Biochem Mol Toxicol 2007;21(04):187-196

57 Wang D, Zou L, Jin Q, Hou J, Ge G, Yang L. Human carboxylesterases: a comprehensive review. Acta Pharm Sin B 2018;8(05): 699-712

58 Merali Z, Ross S, Paré G The pharmacogenetics of carboxylesterases: CES1 and CES2 genetic variants and their clinical effect. Drug Metabol Drug Interact 2014;29(03):143-151

59 Song SH, Chang HE, Jun SH, et al. Relationship between CES2 genetic variations and rifampicin metabolism. J Antimicrob Chemother 2013;68(06):1281-1284

60 Mitchison DA. Plasma concentrations of isoniazid in the treatment of tuberculosis. In: Davies DS, Prichard BN, eds. Biological Effects of Drugs in Relation to their Plasma Concentrations. London: MacMillan; 1973:171-182

61 Ellard GA, Gammon PT. Pharmacokinetics of isoniazid metabolism in man. J Pharmacokinet Biopharm 1976;4(02):83-113

62 Bhandari R, Kaur IP. Pharmacokinetics, tissue distribution and relative bioavailability of isoniazid-solid lipid nanoparticles. Int J Pharm 2013;441(1-2):202-212
63 Hutchings AD, Monie RD, Spragg BP, Routledge PA. Saliva and plasma concentrations of isoniazid and acetylisoniazid in man. $\mathrm{Br}$ J Clin Pharmacol 1988;25(05):585-589

64 Jutte PC, Rutgers SR, Van Altena R, Uges DR, Van Horn JR. Penetration of isoniazid, rifampicin and pyrazinamide in tuberculous pleural effusion and psoas abscess. Int J Tuberc Lung Dis 2004;8(11):1368-1372

65 Conte JE Jr, Golden JA, McQuitty M, et al. Effects of gender, AIDS, and acetylator status on intrapulmonary concentrations of isoniazid. [published correction appears in Antimicrob Agents Chemother. 2002 Sep;46(9):3112.]Antimicrob Agents Chemother 2002; 46(08):2358-2364

66 Singh N, Golani A, Patel Z, Maitra A. Transfer of isoniazid from circulation to breast milk in lactating women on chronic therapy for tuberculosis. Br J Clin Pharmacol 2008;65(03):418-422

67 Wang P, Pradhan K, Zhong XB, Ma X. Isoniazid metabolism and hepatotoxicity. Acta Pharm Sin B 2016;6(05):384-392

68 Khan SR, Morgan AG, Michail K, et al. Metabolism of isoniazid by neutrophil myeloperoxidase leads to isoniazid-NAD $(+)$ adduct formation: a comparison of the reactivity of isoniazid with its known human metabolites. Biochem Pharmacol 2016;106:46-55

69 Rozwarski DA, Grant GA, Barton DH, Jacobs WR Jr, Sacchettini JC. Modification of the NADH of the isoniazid target (InhA) from Mycobacterium tuberculosis. Science 1998;279(5347):98-102

70 Khan N, Pande V, Das A. NAT2 sequence polymorphisms and acetylation profiles in Indians. Pharmacogenomics 2013;14(03): 289-303

71 Preziosi P. Isoniazid: metabolic aspects and toxicological correlates. Curr Drug Metab 2007;8(08):839-851

72 Cheng J, Krausz KW, Li F, Ma X, Gonzalez FJ. CYP2E1-dependent elevation of serum cholesterol, triglycerides, and hepatic bile acids by isoniazid. Toxicol Appl Pharmacol 2013;266(02):245-253

73 Sim E, Payton M, Noble M, Minchin R. An update on genetic, structural and functional studies of arylamine $\mathrm{N}$-acetyltransferases in eucaryotes and procaryotes. Hum Mol Genet 2000;9(16): 2435-2441

74 Blum M, Grant DM, McBride W, Heim M, Meyer UA. Human arylamine $\mathrm{N}$-acetyltransferase genes: isolation, chromosomal localization, and functional expression. DNA Cell Biol 1990;9 (03):193-203

75 Ohsako S, Deguchi T. Cloning and expression of cDNAs for polymorphic and monomorphic arylamine $\mathrm{N}$-acetyltransferases from human liver. J Biol Chem 1990;265(08):4630-4634

76 Windmill KF, Gaedigk A, Hall PM, Samaratunga H, Grant DM, McManus ME. Localization of N-acetyltransferases NAT1 and NAT2 in human tissues. Toxicol Sci 2000;54(01):19-29

77 Sabbagh A, Darlu P, Crouau-Roy B, Poloni ES. Arylamine N-acetyltransferase 2 (NAT2) genetic diversity and traditional subsistence: a worldwide population survey. PLoS One 2011;6(04):e18507

78 Boukouvala S, Sim E. Structural analysis of the genes for human arylamine $\mathrm{N}$-acetyltransferases and characterisation of alternative transcripts. Basic Clin Pharmacol Toxicol 2005;96(05):343-351

79 Hein DW. N-acetyltransferase 2 genetic polymorphism: effects of carcinogen and haplotype on urinary bladder cancer risk. Oncogene 2006;25(11):1649-1658

80 Richardson M, Kirkham J, Dwan K, Sloan D, Davies G, Jorgensen A. Influence of genetic variants on toxicity to anti-tubercular agents: a systematic review and meta-analysis (protocol). Syst Rev 2017;6(01): 142

81 Donald PR, Parkin DP, Seifart HI, et al. The influence of dose and Nacetyltransferase-2 (NAT2) genotype and phenotype on the pharmacokinetics and pharmacodynamics of isoniazid. Eur J Clin Pharmacol 2007;63(07):633-639 